\title{
Comparison of varying complexity numerical models for the prediction of flood inundation in Greenwich, UK
}

T.J. Fewtrell, P.D. Bates, A. de Wit, N. Asselman \& P. Sayers

Reproduced from:

Flood Risk Management - Research and Practice Proceedings of FLOODrisk 2008

Keble College, Oxford, UK

30 September to 2 October 2008 


\title{
Comparison of varying complexity numerical models for the prediction of flood inundation in Greenwich, UK
}

\author{
T.J. Fewtrell \& P.D. Bates \\ Willis Research Network, University of Bristol, Bristol, UK
}

A. de Wit \& N. Asselman

Deltares/Delft Hydraulics, Delft, The Netherlands

P. Sayers

HR Wallingford Ltd, Wallingford, Oxfordshire, UK

\begin{abstract}
In recent years, urban flood modelling studies have taken the form of either validation against observations of a single event or benchmarking models of varying complexity for a synthetic flood event. In this paper, the latter framework is undertaken for hypothetic flooding scenarios at Greenwich on the River Thames, UK. A simple diffusion wave storage cell model, LISFLOOD-FP, is compared to a fully 2D hydrodynamic model, SOBEK, at multiple resolutions for a 1-in-100 year return period event. The models yield consistent results at the highest resolution $(5 \mathrm{~m})$ with minor differences accounted for by inertial effects and model schematisation. Secondly, both models predict significant degradation in model results at coarse resolutions compared to the high resolution benchmark. Specifically, results at 25 and $50 \mathrm{~m}$ suggest different flow structures emerge as the representation of urban structures becomes more coarse. As a result of this finding, the models are setup using a digital terrain model (DTM) with the buildings removed to investigate these emergent flow structures.
\end{abstract}

\section{INTRODUCTION}

Recent severe flood events in the UK, in particular Carlisle in January 2005 and Gloucestershire in the summer of 2007, have raised public, political and scientific awareness of flood risk and the need for effective flood protection and alleviation measures. Furthermore, events across Europe in the summer of 2002 highlighted the need for effective but justifiable flood managements schemes as annual damage estimates far outstretch current management expenditure. The latter is estimated at $£ 800$ million in the UK whereas average annual damage estimates in 2004 were as much as $£ 1,400$ million (Evans et al. 2004). In the UK alone, nearly two million properties are located on floodplains along river, estuaries and coasts and The Department of the Environment, Food and Rural Affairs (DEFRA) further estimate that 200,000 properties are classified as at risk of flooding as they do not have the Government prescribed minimum level of protection against a 1-in-75 year flood event. Furthermore, the Association of British Insurers (ABI) note that member companies have reported a total of 165,000 claims totaling $£ 3$ billion as a result of the summer 2007 floods in the UK (ABI 2007).
Climate change scenarios and development projections suggest that flood risk in Europe is likely to increase. Firstly, sea level rise, increased storm frequency, changing seasonal patterns and an increase in the probability of extreme events mean that low-lying areas will be at greater risk from flooding in future years (IPCC 2007). Secondly, increased public and private development in floodplains will have a dramatic effect on both the annual damage estimates and the distribution of areas at risk. Evans et al. (2004) project as much as $£ 30$ billion of annual damage from fluvial and pluvial flooding by 2080 based on high emission scenarios and current management expenditure. Despite these projections, a recent proposal from the Office of the Deputy Prime Minister details the development of a further 250,000 properties and $\sim £ 500$ million of investment located on floodplains in south east England (ODPM 2005). There is a clear disparity between attitudes towards planning and management and the perception of present and potential flood risk.

Increasing flood risk requires the development and application of an appropriate set of tools to inform local and regional government on management policy, engineers for planning and design purposes and (re-) insurers to calculate exposure. Furthermore, as risk to human 
life and asset value are highest in urban areas, there is a real and current need to develop computationally efficient urban flood models for risk analysis and wide area application. With the increasing availability of high resolution topographic and topological information for urban areas, in the form of LiDAR and MasterMap ${ }^{\circledR}$ data products, two dimensional (2D) flood inundation modelling of urban areas has become feasible.

Recent modelling studies of urban floods have benchmarked models of varying complexity at a single model resolution finding that different classes of model produce plausible but subtly different model results (Hunter et al. 2008). In order to establish a practical approach for developing urban flood models, it is necessary to assess the performance of models of different complexity at different resolutions. To address this need, LISFLOOD-FP, a 2D storage cell based numerical code developed at the University of Bristol (Bates and De Roo 2000; Hunter et al. 2005), and SOBEK, a fully hydrodynamic 2D model using an implicit ADI solver on a structured grid developed at WL Delft Hydraulics (Hesselink et al. 2003), are applied to a $11.5 \mathrm{~km}^{2}$ area of the London tidal risk area. Firstly, the model results at the highest resolution (in this case $5 \mathrm{~m}$ ) are compared to examine the consistency between models and to determine the magnitude of any uncertainties introduced by a simpler scheme. Secondly, models at coarse resolution are constructed in each code to investigate how results from varying complexity codes transfer across scales. Finally, the use of different digital elevation models (DEMs) is explored by comparing results from models using a digital surface model (DSM) including buildings and a digital terrain model (DTM) representing the bare earth without buildings and vegetation.

\section{STUDY SITE}

London is home to 7.5 million people, with 1 million people and 300,000 properties in the tidal flood risk area (Dawson et al. 2005). The indicative tidal flood risk area for the Thames Region of the Environment Agency (EA) lies between Teddington Weir and Dart-ford Creek (approx. $116 \mathrm{~km}^{2}$ ) (Figure 1) and would be liable to frequent flooding from surge tides without the existing tidal walls and embankments. London is defended by a complex system of over $200 \mathrm{~km}$ of embankments and walls, the Thames Barrier and a suite of warning systems. However, recent development in London's previously derelict docklands and the emergence of the the new financial district around Canary Wharf combined with plans for significant future development over the next 15-30 years (ODPM 2005) poses significant questions over future flood risk.

Hall et al. (2003) note that flood risk in estuaries is dominated either by defence overflow, which can be

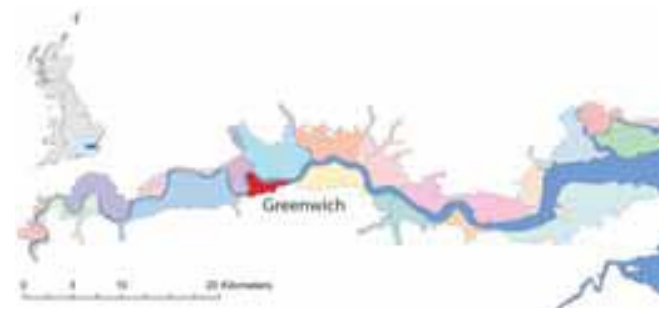

Figure 1. Map of the EA indicative tidal flood risk area of the Thames Region highlighting the Greenwich study area. Data courtesy of EA Thames Region.

calculated using standard weir equations, or defence breaching, which requires assessment of defence integrity and inundation probabilities. The latter requires an additional computational burden (Hall et al. 2003). Dawson et al. (2005) note that if extreme sea level rise scenarios are considered for flood risk assessment, the contribution to total inundation volume from breaching is negligible compared to the inundation volume from overflow events. The same authors found significant increases in flood risk to London and the surrounding Thames region from comparatively small increases in sea level. Furthermore, Gouldby et al. (2007) note that the flood defences along the River Thames are in good condition and thus breach events are less likely than overtopping scenarios which supports the need for modelling of individual areas to assess detailed flood risk.

For flood management purposes, the EA delimit the tidal flood risk area into embayments which are considered to be in hydraulic isolation from each other, with high ground, tributaries or artificial contraining features extending from inland to the river Thames to form boundaries between embayments. In order to investigate detailed urban flood risk, the Greenwich embayment is chosen as a suitable study site indicative of defence integrity and urban topography and topology for the wider Thames tidal flood risk region (see Figure 1). The $11.5 \mathrm{~km}^{2}$ embayment is characterised by areas of densely clustered terraced housing and large industrial units and machinery surrounded by substantial open spaces. Furthermore, the embayment incorporates significant assets (i.e. $\mathrm{O}_{2}$ Arena and the Blackwall Tunnel) and flooding of these features would cause substantial business and service interruption for the UK's capital.

\section{MODEL DESCRIPTION}

\subsection{Model parameterisation}

The Environment Agency provided the LiDAR data survey for this site, flown in March 1999 and 


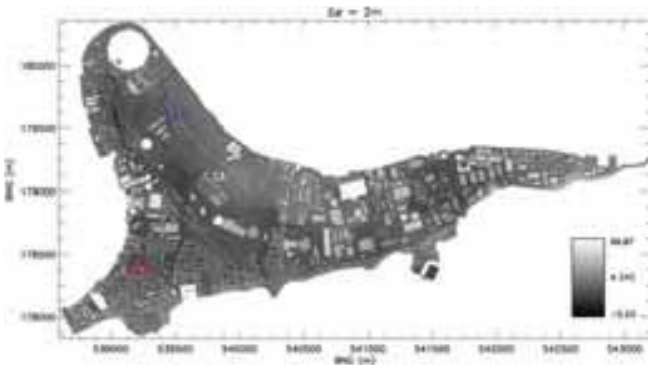

Figure 2. Digital elevation model of Greenwich embayment processed using the EA in-house segmentation and manual intervention including buildings and vegetation at $\Delta x=2 \mathrm{~m}$.

collected at $2 \mathrm{~m}$ resolution, through the FLOODsite project. In order to increase the utility of LiDAR data, the EA have developed an in-house segmentation algorithm that delivers a DSM, a DTM and a mask of buildings and vegetation based on pattern recognition in the raw LiDAR signal. The EA also perform a significant amount of manual processing to remove bridges and elevated road sections that would otherwise form artificial blockages to flood propagation. Figure 2 shows the $2 \mathrm{~m}$ resolution digital elevation model for the Greenwich embayment processed by the Environment Agency.

The simulation of overtopping and breach scenarios for hydraulic modelling of individual flood embayments was conducted by HR Wallingford Ltd using a model based on the RASP procedure (Hall et al. 2003). This method involves the development of fragility curves which integrates a full range of loading conditions (water levels) with the performance and integrity of flood defences (Gouldby et al. 2007). Each defence section is considered independent and has a different resistance to flood loading which is characterised by structure type, crest level or condition. The fragility curve for each defence section, defined as a continuous random variable of defence failure conditional on the load, was derived from failure models for either overflow or piping, or a combination thereof. The occurrence of extreme water levels is defined as a continuous random variable associated with each defence section. The defence system state (failed/not failed) is calculated using a Monte Carlo framework where the defence state is sampled with reference to the defence specific fragility curve for a given loading. Peak flow rates into the floodplain for each defence are calculated using the broad-crested weir equation and transformed to triangular hydrographs of duration equal to the breach duration (Gouldby et al. 2007) (Figure 3).

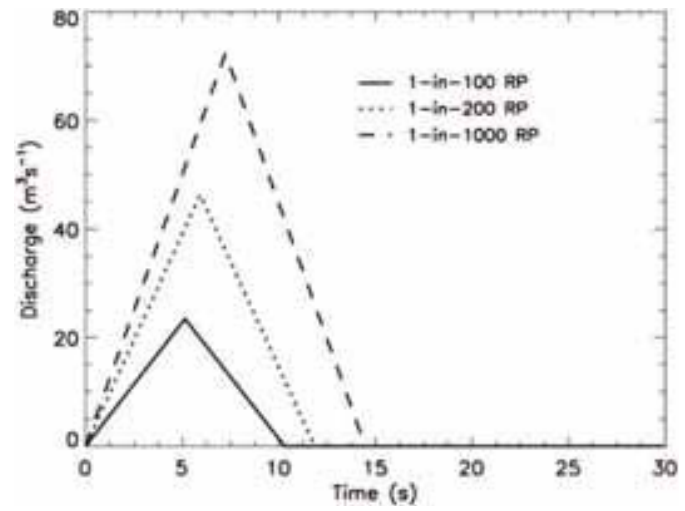

Figure 3. Example event hydrographs used for the Greenwich embayment derived from the HR Wallingford Ltd breach model for the maximum breach flow generated across all defences for the 1-in-100, 200 and 1000 year return period events with 2 defence failures.

\subsection{Modelling framework}

In order to investigate the effect of different complexity models on predictions of flooding, two models indicative of their class were chosen. LISFLOOD-FP is a classic diffusion wave storage cell approximation, indicative of models used at engineering consultancies (e.g. JFLOW at JBA) and in the insurance industry (e.g. RMS UK River Flood), with the added advantage of being unconditionally stable without the need for flux limiting. SOBEK is a finite difference model solving the full St. de Venant equations on a staggered, structured grid. A short description of these models is provided below as more detailed descriptions can be found elsewhere (see Bates and De Roo (2000) for LISFLOOD-FP and Hesselink et al. (2003) for SOBEK).

\subsubsection{LISFLOOD-FP}

Building on early studies using a 2D diffusion wave approximation of floodplain flow (e.g. Xanthopoulos and Koutitas 1976; Hromadka and Yen 1986), a number of raster-based models have been developed to exploit high resolution topography data available through LiDAR. These models generally employ a $1 \mathrm{D}$ representation of channel flow linked to a $2 \mathrm{D}$ representation of floodplain flow, commonly involving a diffusion-wave treatment (Yu and Lane 2006a). Bates and De Roo (2000) developed the raster-based model LISFLOOD-FP which uses a 1D kinematic wave equation for channel flow linked to a $2 \mathrm{D}$ representation of floodplain flows calculated using an analytical flow equation (Manning's equation). The flow between floodplain elements is calculated using the continuity equation (1) and Manning's equation (2). 
$\frac{\partial h}{\partial t}=\frac{\partial Q_{x}}{\partial x}+\frac{\partial Q_{y}}{\partial y}$

where

$Q_{x}=\frac{h_{\mathrm{flow}}^{5 / 3}}{n}\left(\frac{\Delta h}{\Delta x}\right)^{1 / 2} \Delta y$

where $Q$ is the flow between floodplain cells $\left(\mathrm{m}^{3} \mathrm{~s}^{-1}\right)$, $h$ is the height of water in any given cell $(m), \Delta x$ and $\Delta y$ are the grid spacings $(m)$ and $n$ is Manning's friction parameter.

Hunter et al. (2005) noted that this model portrays instabilities in areas of deep water and may be subject to oscillations between cells as a result of the prescribed time-step (explored in more detail in Cunge et al. (1980)). Furthermore, a number of studies showed an insensitivity to floodplain friction parameterisation (Horritt and Bates 2001; Hunter et al. 2005). Therefore, an adaptive time-step algorithm based on considerations of model stability, analagous to a Courant-Freidrichs-Levy condition for advective flows, was developed. This yields an optimal time step that is controlled by the grid spacing $(\Delta x)$ and the depth available for flow $\left(h_{\text {flow }}\right)$. As the timestep $(\Delta t)$ is a quadratic function of the grid size $(\Delta x)$, this method comes at a high computational cost when applied on the high resolution grids currently need to resolved flows in urban environments.

\subsubsection{SOBEK}

SOBEK is a $2 \mathrm{D}$ hydrodynamic inundation model discretised using finite differences solving the full shallow water equations on a staggered spatial grid (Hesselink et al. 2003). The continuity equation is approximated such that (i) mass is conversed not only globally, but also locally and (ii) water depths are forced positive which precludes the need for specific wetting and drying algorithms (see Horritt (2002)). Mass is conserved as in Eqn 1 and momentum is conserved (in the $\mathrm{x}$-direction) as follows:

$$
\frac{\partial u}{\partial t}+u \frac{\partial u}{\partial x}+v \frac{\partial u}{\partial x}+g \frac{\partial \zeta}{\partial x}+g \frac{u\|u\|}{C^{2} h}=0
$$

where $u$ and $v$ are velocities in the $\mathrm{x}$-and $\mathrm{y}$-directions respectively, $C$ is the Chezy friction coefficient, $\zeta$ is the water level above a plane of reference and $h$ is the water elevation. The same equation can be written for the y-direction (Stelling 2002).

Hesselink et al. (2003) present two methods for mass, momentum and energy head conservation across discontinuities where the energy head conservation is used in areas of significant flow constrictions and the mass and momentum conservation method is
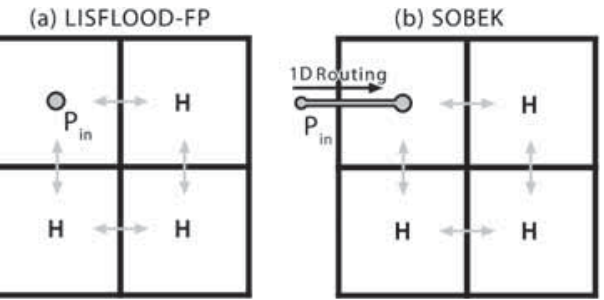

Figure 4. Schematisation of model inflow boundary conditions for (a) LISFLOOD-FP and (b) SOBEK where $P$. denotes the inflow point and $H$ denotes water heights. Note the inclusion of $1 \mathrm{D}$ channel routing in SOBEK

used everywhere else. Time integration is performed using an alternating direction implicit (ADI) scheme. Furthermore, flooding over an initially dry bed uses a predictor corrector approach to prevent overshoot of the velocities if the velocity accelerates from zero at a discontinuity (Hesselink et al. 2003). SOBEK has been shown to provide consistent results when compared to laboratory experiments of dam break scenarios (Stelling 2002).

\subsection{Model schematisation}

In order to ensure consistent comparison of model results, LISFLOOD-FP and SOBEK were schematised as similarly as possible although a few subtle differences remain which are unavoidable and detailed below. The breach flows provided by HR Wallingford Ltd. represent the volume of water flowing over the defence and/or through the breach over the duration of the event. Therefore, these flows should be input directly into any model representing the overland flow component of the flooding. Representing this process in LISFLOOD-FP is straightforward as a point source flux can be assigned at any given location in the domain such that the overtopping/breach flow is specified at the defence location (see Fig. 4a). In SOBEK, the model is schematised such that a one dimensional (1D) channel with a prescribed bottom elevation is required to route the flow into the 2D domain (see Fig. 4b). It should be noted that this requires a certain amount of modeller skill, can be time consuming to implement. This may result in timing differences between the two models.

\section{RESULTS AND DISCUSSION}

Fewtrell et al. (in press) note that modelling of urban flooding requires detailed information on urban fabric $a$ priori to determine the appropriate scale of representation given computational and resolution requirements. Urban areas are characterised by structures of varying 
dimensions and size as well as differing separation distances. Figure 5 shows the distribution of length scales in the Greenwich embayment suggesting the shortest axis of most buildings is $\sim 15 \mathrm{~m}$ but that these buildings are a minimum of $\sim 5 \mathrm{~m}$ apart. As a consequence, in order to fully resolve the complex flow features prevalent during urban floods, and in particular, during rapid flood wave propagation caused by breaching of defence structures, a model grid resolution at least as high as this shortest length scale should be used. Consequently, a grid resolution of $5 \mathrm{~m}$ was chosen to act as the benchmark resolution at which to assess the differences between the two models and to investigate their scaling behaviour. Furthermore, as there is no validation data for this event, coarse resolution model configurations will be assessed against the high resolution benchmark as a form of model verification (see Lane and Richards (2001)).

\subsection{High resolution benchmark simulations}

Figure 6 shows the maximum predicted water heights after 50 mins simulation time from LISFLOOD-FP and SOBEK. Firstly, the most noticeable artefact is the similarity of predicted flood extents between the two models. LISFLOOD-FP predicts $0.510 \mathrm{~km}^{2}$ of flooded area at maximum extent and SOBEK pre-
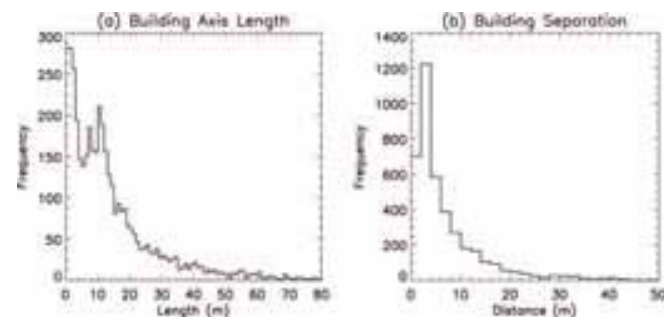

Figure 5. Distribution of length scales in the Greenwich embayment where (a) is the distribution of shortest building dimension derived from MasterMap ${ }^{\circledR}$ and (b) shows the distribution of shortest distance between buildings. dicts $0.515 \mathrm{~km}^{2}$, a difference of $0.005 \mathrm{~km}^{2}$ and a mere 171 computational cells out of a total of 159071 . The individual flow paths predicted by the two models are also similar as both models are structured, finite difference spatial discretisations and thus retain the gridded nature of the LiDAR product in similar ways. However, it would appear that although LISFLOODFP predicts a smaller flooded area, flood propagation down distinct flow paths is more rapid (see $[1000,1250]$ and $[2500,750])$.

Secondly, the maximum water depths predicted near the flood boundary are higher in LISFLOOD-FP than predicted by SOBEK as would be expected from more rapid flood propagation observed in the former. Figure 7 highlights this artefact further by displaying the time evolution of predicted water depths through contrasting regions of the study site. Section \#1 (see 2 for locations) is an area of open, paved land that is the concourse for the $\mathrm{O}_{2}$ Arena (Millenium Dome) and section \#2 is a distinct, narrow street in an area of dense residential housing. The differences in predicted water depths between the two models along section \#1 are of the order of $\sim 5 \mathrm{~cm}$ at peak increasing to $\sim 10 \mathrm{cms}$ during floodwave recession. Furthermore, the models predict significant differences in the timing of flooding with LISFLOOD-FP predicting faster wave arrival close to the defence section and the SOBEK wave arriving sooner further inland. The former difference can be explained by the use of a 1D channel to route flow into the domain in SOBEK and the latter is explained by the lack of local acceleration terms in the LISFLOOD-FP governing equations as demonstrated by Hunter et al. (2007). The same differences are observed along section \#2, despite differences in hydraulic properties, with LISFLOOD-FP predicting higher water depths compared to SOBEK.

Consideration of the relationship between flood depth and associated damage suggests certain thresholds exist when addressing damage in residential areas. Namely, the level at which water enters the property and subsequently, the level at which water impacts electrical fittings at $\sim 20-30 \mathrm{~cm}$. Figure 8 shows the
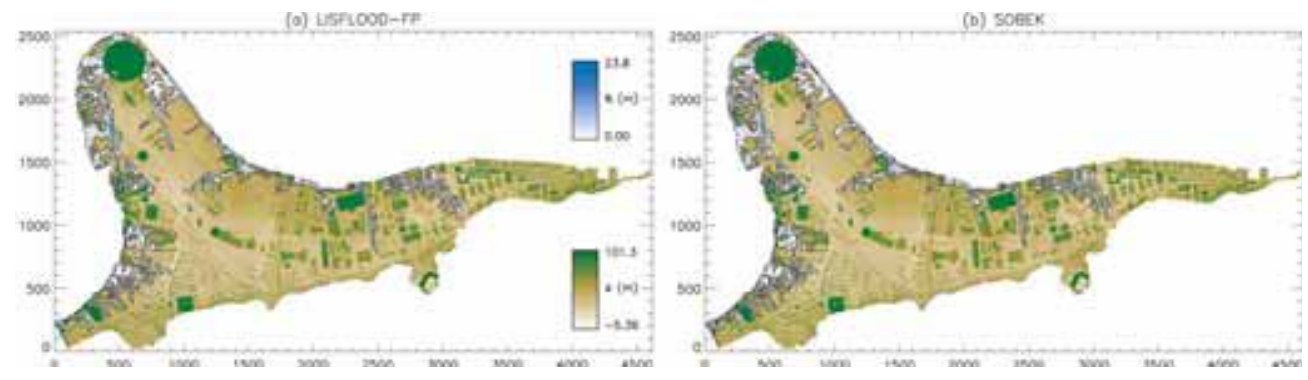

Figure 6. Maximum simulated water depths and flood extent from the high resolution, benchmark $5 \mathrm{~m}$ simulation from (a) LISFLOOD-FP and (b) SOBEK with the surface height (z) from the DEM overlain by water depths (h). 
(a) Section 1

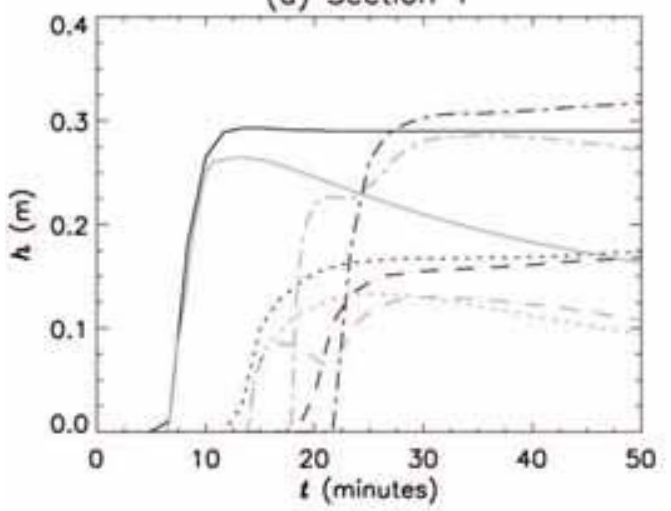

(b) Section 2

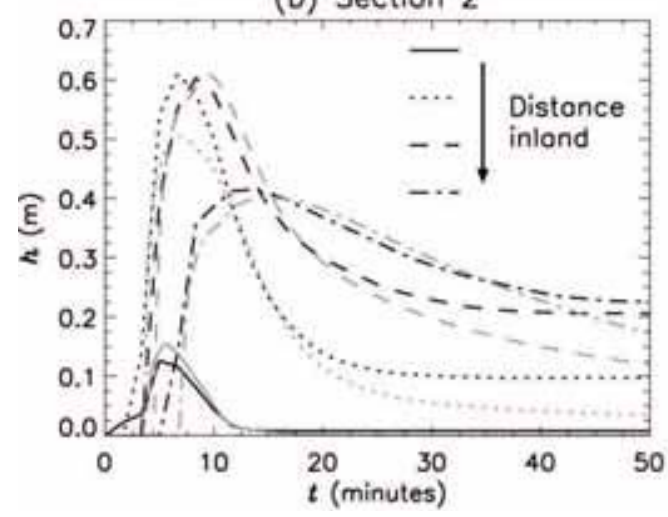

Figure 7. Time evolution of predicted water depths along two sections extending inland from the defence failure point with LISFLOOD-FP results shown in black and SOBEK results shown in grey. Refer to Figure 2 for location of sections.

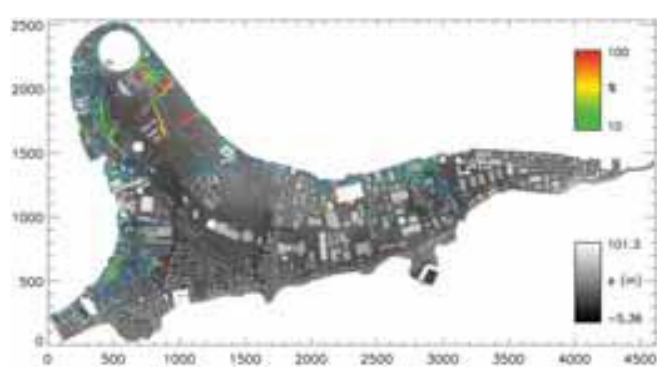

Figure 8. Differences in predicted water depths between LISFLOOD-FP and SOBEK expressed as a percentage of the maximum predicted water depth on a cell-by-cell basis. The maximum predicted flood extent predicted by SOBEK is denoted by the blue contour. Note that the first $10 \%$ of differences are displayed as transparent. absolute difference in water heights between the two models as a percentage of the maximum water depth predicted by either model. The green represents areas where the difference between model solutions is 20\% of the total depth and the red areas are where one model predicts wet and the other predicts dry. In order to aid visualisation, differences up to $10 \%$ are displayed transparent within the extent outline of the SOBEK solution. The majority of differences between the two models are less than $10 \%$ of the maximum depth and therefore have little impact on damage estimates for residential housing. However, the areas where the models disagree significantly are areas of paved, open land and roads where direct damage estimates will be low but may impact substantially on indirect damage estimates (e.g. business interruption).

Although the models provide very similar results at this benchmark resolution, SOBEK generates the simulation results within 18 hours whereas the LISFLOOD-FP stability criterion yields a simulation time of 9 days. Furthermore, SOBEK is a more physically based solution and thus is more practical for industry and commercial use.

\subsection{Effects of model resolution}

Near real-time flood forecasting requires computationally efficient model codes to provide estimates of flood depths and extent for the ensemble of predicted flow forecasts. Considering the computational cost of high resolution solutions in both LISFLOOD-FP and SOBEK, the scaling behaviour and performance of the two models requires investigation. The high resolution $2 \mathrm{~m}$ DSM was resampled to resolutions of 10 , 25 and $50 \mathrm{~m}$ using a nearest neighbour resampling strategy (see Yu and Lane (2006a) and Fewtrell et al. (in press)). Figure 9 shows the maximum predicted flood extents predicted by the degraded models for the regions around section \#1 (a \& c) and section \#2 (b \& d) for the two model codes. Notably, in areas of open land $(\mathrm{a} \& \mathrm{c})$, the two models predict similar flow patterns at similar model scales and substantially over-predict the benchmark solution at 25 and $50 \mathrm{~m}$. Furthermore, both models portray a similar amount of degradation in model performance at the each model resolution although LISFLOOD-FP suffers from more numerical diffusion that SOBEK.

The coarse resolution results at section \#2, however, show significant changes in flow patterns as the coarse representation of urban media reduces the area available for flow and closes off flow paths apparent at higher resolutions (Figures 9b \& d). Furthermore, there are substantial differences between model predictions at $50 \mathrm{~m}$ where LISFLOOD-FP predicts more flooding in this region, and over the domain as a whole at 25 and $50 \mathrm{~m}$, than SOBEK. This discrepancy may be caused by using the $1 \mathrm{D}$ channel routing with 
(a) LISFLOOD-FP

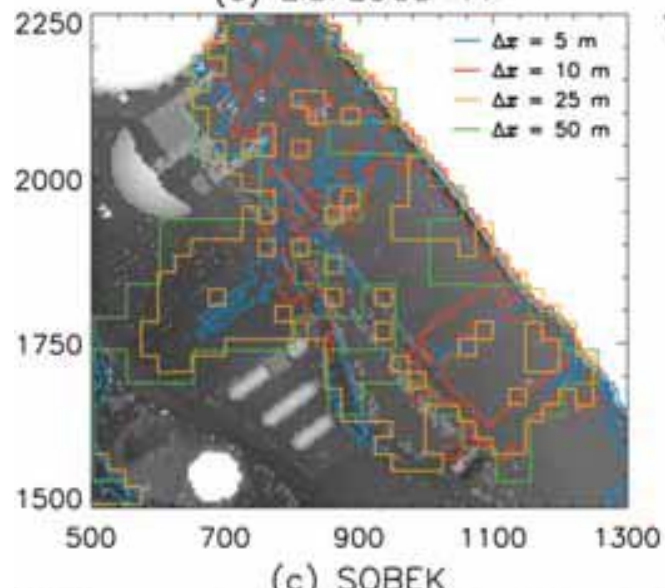

SOBEK

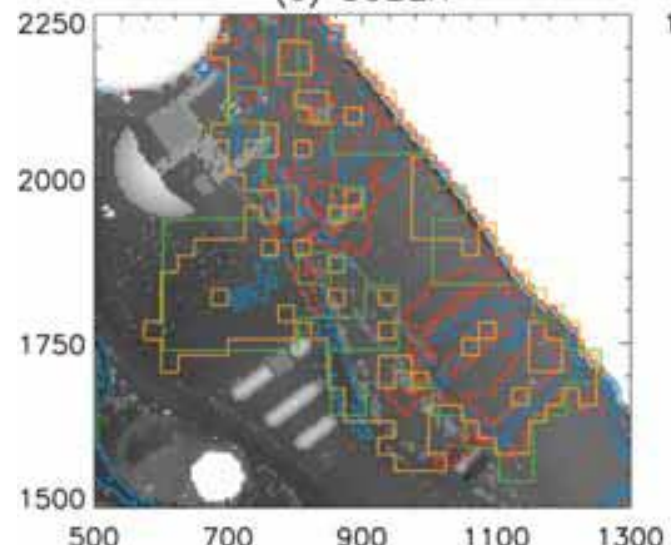

(b) LISFLOOD-FP

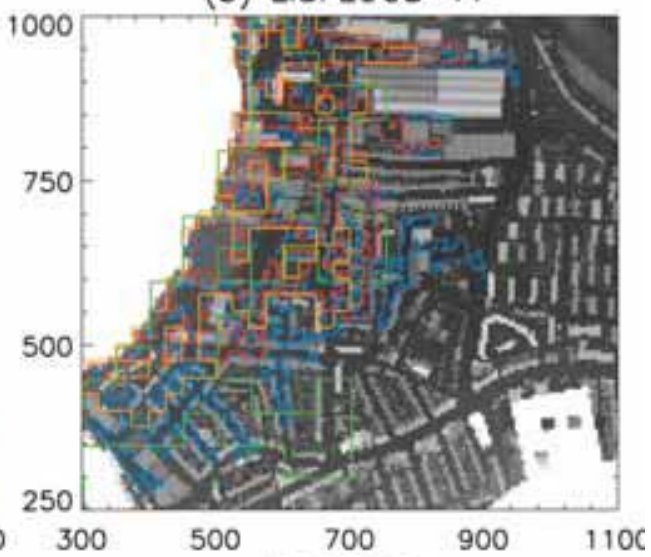

(d) SOBEK

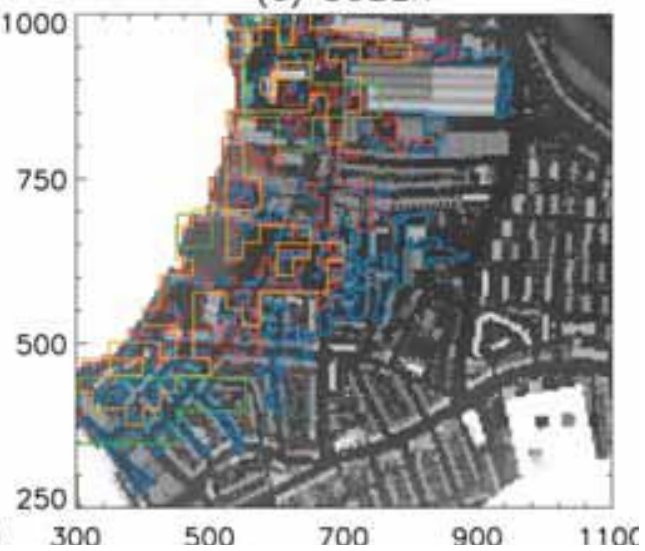

Figure 9. Maximum predicted flood extents for LISFLOOD-FP and SOBEK at $\Delta x=5,10,25$ and $50 \mathrm{~m}$ for the regions around section \#1 (a \& c) and section \#2 (b \& d).

a bottom elevation that relates to the high resolution grid rather than the coarse resolution grid [Natalie/ Anneloes to confirm this].

Analysis of the time evolution of water depths predicted along the two sections at different resolutions (Figure 10) shows substantial timing, flow direction and peak flow differences on coarse grids including buildings compared to the high resolution benchmark. This suggests that coarse grids cannot be used to predict the important aspects of flooding. The marked difference in scaling behaviour between LISFLOODFP and SOBEK in open areas and down defined flow paths are confirmed here as water height evolution at 25 and $50 \mathrm{~m}$ is substantially different between models and areas but similar at 5 and $10 \mathrm{~m}$.

The emergence of different flow patterns at coarse resolutions suggests that floodplain structures are degraded to such an extent that the flow paths are altered so significantly that a flood map similar to the benchmark realisation is not achievable. Therefore, it may be possible to parameterise the model topography using a coarse resolution, 'bare earth' elevation model with the buildings removed so as to remove these artificial blockages and flow paths. This may allow the benchmark flow patterns and water depths to be resolved with coarse topographic representation.

\subsection{Effects of topographic representation}

Figure 11 shows the time evolution of predicted water depths at points along section \#1 (a \& b) and section \#2 (c \& d) using the elevation data with (DSM) and without buildings (DTM). Notably, at $25 \mathrm{~m}$, the 'bare earth' topography predicts similar water heights as the surface model with buildings whereas at $50 \mathrm{~m}$ resolution, there are substantial differences between 

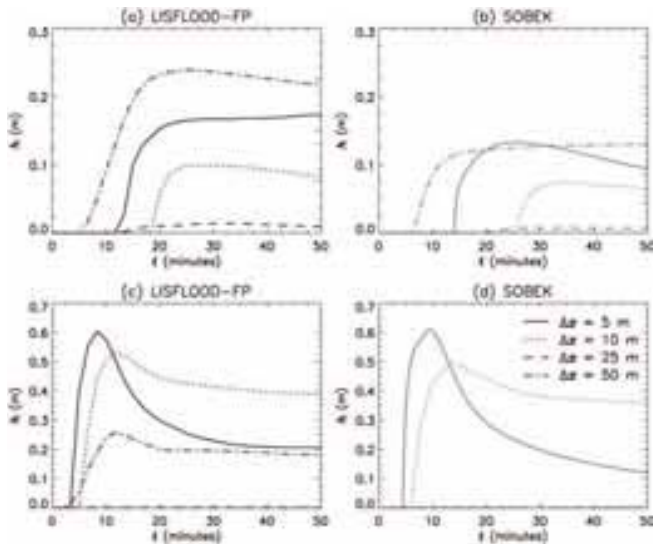

Figure 10. Time evolution of water depths at ax $=5,10,25$ and $50 \mathrm{~m}$ for the two models at one point along section \#1 ( $\mathrm{a} \& \mathrm{c})$ and \#2 (b \& d).
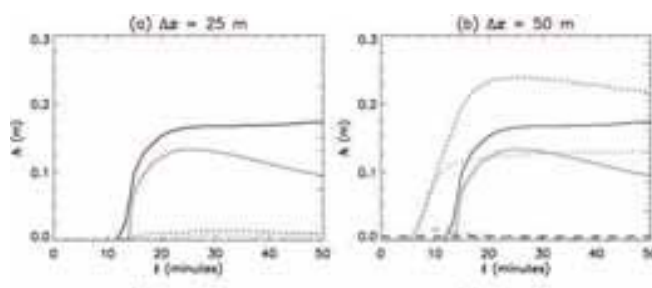

(c) $A s=2 s$
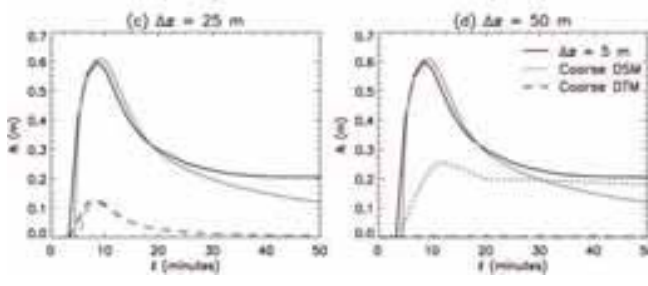

Figure 11. Time evolution of water depths along section $\# 1$ (a \& c) and \#2 (b \& d) using $\Delta x=25$ and $50 \mathrm{~m}$ digital surface (with buildings and vegetation) and terrain (bare earth) models.

the two topographic sets. In regions of open land, the digital terrain model provides no advantages over the original surface model. This is expected as LiDAR segmentation of areas of open land should not significantly change between surface and 'bare earth' configurations. However, where significant flow paths are prevalent in the high resolution topography, the use of 'bare earth' topography for coarse resolution modelling yields some improvements in stage predictions (Figure 11c). Furthermore, with the exception of Figure $11 \mathrm{~b}$, SOBEK and LISFLOOD-FP provide commensurate results for both topographic data sets.
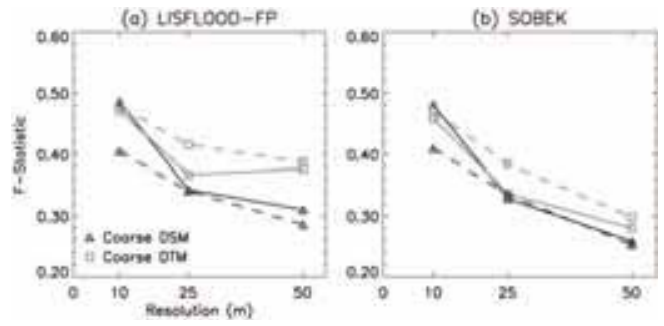

Figure 12. Fit between predicted and benchmark inundated area at $\Delta x=10,25$ and $50 \mathrm{~m}$ for the two models with the default results represented by the solid line and the reprojected results represented by the dashed line.

Horritt and Bates (2001) showed that reprojecting results from a coarse resolution model onto a high resolution grid, provides improved estimates of flood extent compared to the original coarse resolution solutions. Figure 12 shows the change in a binary global performance measure, $F^{2}$ (Aronica et al. 2002), for the coarse elevation models compared to the high resolution benchmark simulation at maximum extent. The dashed line here represents the fit to the benchmark simulation once the water depths have been reprojected onto the high resolution digital surface model. It would appear that reprojecting results from a coarse digital terrain model at $\Delta x=25$ and $50 \mathrm{~m}$ substantially improves the global estimate of flood extent compared to DSM results, both standard and re-projected. However, damage estimates from flooding episodes rely on detailed and accurate measurements and/or predictions of water depth. The reprojection of coarse resolution results on fine grids does not yield reliable estimates of peak water levels or flood duration as a substantial amount of water is unaccounted for after reprojection. Therefore, an intelligent reprojection strategy should be developed to redistribute this excess volume throughout the domain to attempt to reconcile water depths and flood duration.

\section{CONCLUSIONS}

A comparison of two models of varying complexity on a hypothetical 1-in-100 year return period flooding episode at Greenwich, UK is presented. LISFLOODFP is a diffusion wave storage cell model and SOBEK is a 2D finite difference model solving the full de St. Venant equations. Driving both models with a high resolution $(5 \mathrm{~m})$ topographic data set yields similar results, in terms of both water depths and flood extents. Floodwave propagation is more rapid in LISFLOODFP but the majority of differences in flood depth predictions are less than $10 \%$ of 
the maximum predicted cell at that location. As suggested by Hunter et al. (2007), these differences arise from the lack of representation of inertial effects in LISFLOOD-FP but may also stem from schematisation differences between the two models.

Fewtrell et al. (in press) note that the application of hydraulic models to urban floods should be driven by the characteristics of the urban media in terms of building size and the distance between floodplain structures. At the Greenwich site, model grids up to $10 \mathrm{~m}$ appear to capture the main facets of flooding but there is significant degradation of model results at 25 and $50 \mathrm{~m}$. Use of a digital terrain model to remove artificial blockage effects in coarse resolution DSMs does not appear to reconcile water depths or flood extents. Therefore, it would appear that the loss of topographic information at coarse scales in an urban environment precludes their use for practical flood prediction. A number of authors $\mathrm{Yu}$ and Lane 2006b; McMillan and Brasington 2007; Braschi et al. 1989 have shown the use of developing methods to retain high resolution topographic data at coarse resolutions.

Figure 13 shows increasing model efficiency (event length/computational time) with decreasing model resolution so that an efficiency of greater than 1 means the computational time is less than the length of the flood event. LISFLOOD-FP was originally designed to provide significant computational advantages on large grids at coarse resolution, which is highlighted here. However, on the high resolution grids required to resolve the complex flow patterns of

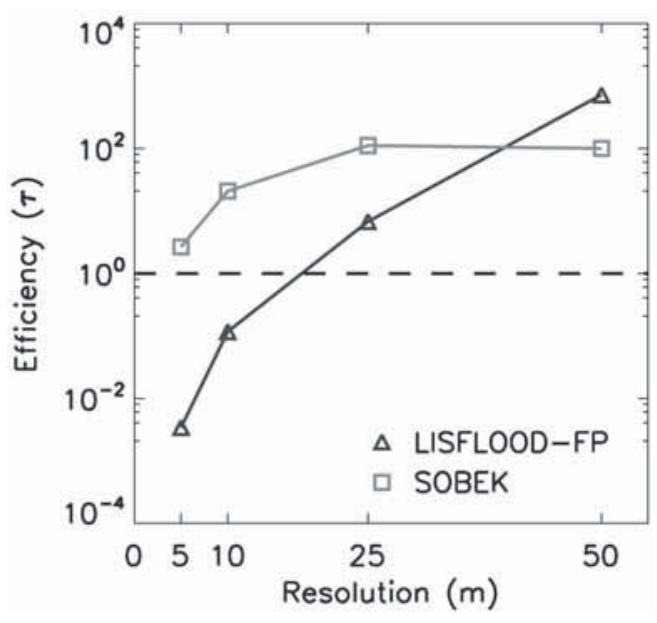

Figure 13. Model efficiency as a function of decreasing model resolution with the black line representing LISFLOOD-FP and the grey line representing SOBEK. Note the $\log$ scale of the $y$-axis. urban areas, full 2D codes provide significant computational and process representation improvements.

\section{ACKNOWLEDGEMENTS}

The work reported in this paper was funded by NERC CASE award NER/S/C/2004/12783 and the FLOODsite project (\#GOCE-CT-2004-505420). The authors wish to thank Halcrow for their funding in conjunction with the NERC CASE award and Willis for their funding through the Willis Research Network. The authors are also extremely grateful to HR Wallingford Ltd., the Environment Agency and the UK Ordnance Survey for provision of data for this project. Further thanks to numerous colleagues for countless revisions of various manifestations of this paper.

\section{REFERENCES}

ABI (2007, 04/12/07). Summer floods 2007: Learning the lessons. Technical report, Association of British Insurers.

Aronica, G., Bates, P.D. and M.S. Horritt (2002). Assessing the uncertainty in distributed model predictions using observed binary pattern information within glue. Hydrological Processes 16(10), 2001-2016.

Bates, P.D. and A.P.J. De Roo (2000). A simple rasterbased model for flood inundation simulation. Journal of Hydrology 236(1-2), 54-77.

Braschi, G., M. Gallati, and L. Natale (1989). Simulation of a road network flooding. In 20th Annual Pittsburgh Conference on Modeling and Simulation, Volume 4, Pittsburgh, USA, pp. 1625-1632.

Cunge, J., F. Holly, and A. Verwey (1980). Practical aspects of computational river hydraulics. London: Pitman Publishing.

Dawson, R.J., J.W. Hall, P.D. Bates, and R.J. Nicholls (2005). Quantified analysis of the probability of flooding in the thames estuary under imaginable worst-case sea level rise scenarios. International Journal of Water Resources Development 21(4), 577-591.

Evans, E., R. Ashley, J. Hall, E. Penning-Rowsell, P. Sayers, C. Thorne, and A. Watkinson (2004). Foresight. Future Flooding. Scientific Summary: Volume II Managing future risks. London: Office of Science and Technology.

Fewtrell, T., P. Bates, M. Horritt, and N. Hunter (in press). Evaluating the effect of scale in flood inundation modelling in urban environments. Hydrological Processes.

Gouldby, B., P. Sayers, O. Tarrant, and D. Kavanagh (2007, April). Thames Estuary 2100: Performance based asset management. Technical Report IA8/10, HR Wallingford.

Hall, J.W., R.J. Dawson, P.B. Sayers, C. Rosu, J.B. Chatterton, and R. Deakin (2003). A methodology for nationalscale flood risk assessment. Proceedings of the Institution of Civil Engineers-Water and Maritime Engineering 156(3), 235-247.

Hesselink, A.W., G.S. Stelling, J.C.J. Kwadijk, and H. Middelkoop (2003). Inundation of a dutch river polder, sensitivity analysis of a physically based inundation 
model using historic data. Water Resources Research 39(9), 1234

Horritt, M.S. (2002). Evaluating wetting and drying algorithms for finite element models of shallow water flow. International Journal for Numerical Methods in Engineering 55(7), 835-851.

Horritt, M.S. and P.D. Bates (2001). Effects of spatial resolution on a raster based model of flood flow. Journal of Hydrology 253(1-4), 239-249.

Hromadka, T.V. and C.C. Yen (1986). A diffusion hydrodynamic model (DHM). Advances in Water Resources 9(3), $118-170$.

Hunter, N.M., P.D. Bates, M.S. Horritt, and M.D. Wilson (2007). Simple spatially-distributed models for predicting flood inundation: A review. Geomorphology 90(3-4), 208-225.

Hunter, N.M., P.D. Bates, S. Neelz, G. Pender, I. Villanueva, N.G. Wright, D. Liang, R.A. Falconer, B. Lin, S. Waller, A.J. Crossley, and D.C. Mason (2008). Benchmarking 2d hydraulic models for urban flooding. Proceedings of the Institution of Civil Engineers-Water Management 161(1), 13-30.

Hunter, N.M., M.S. Horritt, P.D. Bates, M.D. Wilson, and M.G.F. Werner (2005). An adaptive time step solution for raster-based storage cell modelling of floodplain inundation. Advances in Water Resources 28(9), 975-991.

IPCC (2007). Climate Change 2007: Synthesis Report. Contribution of Working Groups I, II and III to the Fourth Assessment Report of the Intergovernmental Panel on Climate Change. Geneva, Switzerland: IPCC.
Lane, S.N. and K. Richards (2001). The validation of hydrodynamic models: some critical perspectives. In M. Anderson (Ed.), Model validation: perspectives in hydrological science, pp. 413-438. Chichester: John Wiley \& Sons.

McMillan, H.K. and J. Brasington (2007). Porosity techniques and flooding in cambridge. Geomorphology 90 , 226-243.

ODPM (2005). Delivering growth in Thames Gateway and the Growth Areas. Technical report, Office of The Deputy Prime Minister.

Stelling, G.S. (2002). A numerical method for inundation simulations. In M.L. Spaulding (Ed.), Proceedings of the Seventh International Conference on Estuarine and Coastal Modelling, Volume 268, pp. 872-892. ASCE.

Xanthopoulos, T. and C. Koutitas (1976). Numericalsimulation of a 2 dimensional flood wave-propagation due to dam failure. Journal of Hydraulic Research 14(4), 321-331.

Yu, D. and S.N. Lane (2006a). Urban fluvial flood modelling using a two-dimensional diffusion-wave treatment, part 1: mesh resolution effects. Hydrological Processes 20(7), 1541-1565.

Yu, D. and S.N. Lane (2006b). Urban fluvial flood modelling using a two-dimensional diffusion-wave treatment, part 2: development of a sub-grid-scale treatment. Hydrological Processes 20(7), 1567-1583. 


\title{
Fluid thinking...smart solutions
}

HR Wallingford provides world-leading analysis, advice and support in engineering and environmental hydraulics, and in the management of water and the water environment. Created as the Hydraulics Research Station of the UK Government in 1947, the Company became a private entity in 1982, and has since operated as a independent, non profit distributing firm committed to building knowledge and solving problems, expertly and appropriately.

Today, HR Wallingford has a 50 year track record of achievement in applied research and consultancy, and a unique mix of know-how, assets and facilities, including state of the art physical modelling laboratories, a full range of computational modelling tools, and above all, expert staff with world-renowned skills and experience.

The Company has a pedigree of excellence and a tradition of innovation, which it sustains by re-investing profits from operations into programmes of strategic research and development designed to keep it - and its clients and partners - at the leading edge.

Headquartered in the UK, HR Wallingford reaches clients and partners globally through a network of offices, agents and alliances around the world.

\section{HR Wallingford}

Working with water

\author{
HR Wallingford Ltd \\ Howbery Park \\ Wallingford \\ 0xfordshire 0X10 8BA \\ UK
tel $\quad+44(0) 1491835381$
fax +44 (0)1491832233
email info@hrwallingford.co.uk

\section{www.hrwallingford.co.uk}

